\title{
Cultural and Morphological Variability and Identification of Anastomosis Group of Rhizoctonia solani (Thanatephorus cucumeris) Causing Sheath Blight of Rice in Kashmir
}

\author{
Mohammad Najeeb Mughal*, Sabiya Bashir, Nazir A. Bhat and K.A. Bhat \\ Division of Plant Pathology, S. K. University of Agricultural Sciences and Technology of \\ Kashmir, Srinagar-190025, India \\ *Corresponding author
}

\begin{tabular}{|c|c|}
\hline & A B S T R A C T \\
\hline $\begin{array}{l}\text { Ke y w o r d s } \\
\text { Cultural, } \\
\text { Morphological } \\
\text { characters, } \\
\text { Anastomosis } \\
\text { grouping, Rhizoctonia } \\
\text { solani. } \\
\end{array}$ & \multirow{3}{*}{$\begin{array}{l}\text { Twenty seven isolates of Rhizoctonia solani collected from different locations across five } \\
\text { districts of Kashmir valley were observed for cultural and morphological variation and } \\
\text { identification of anastomosis group causing sheath blight of rice in Kashmir. The isolates } \\
\text { belonged to five cultural and morphological groups designated as A, B, C, D and E on the } \\
\text { basis of colour of mycelium, growth rate, colour of sclerotia, average size of sclerotia and } \\
\text { pattern of sclerotia formation. Isolate Shb 4, Shb 6, Shb 10, Shb 14, Shb } 18 \text { and Shb } 24 \\
\text { belonged to group A, while isolate Shb 3, Shb 5, Shb 9, Shb 12, Shb 13, Shb 15, Shb 16, } \\
\text { Shb 20, Shb } 22 \text { and Shb } 23 \text { belonged to group B. Group C comprised of isolates Shb 7, } \\
\text { Shb 11, Shb } 21 \text { and Shb } 25 \text { whereas group D and group E comprised of isolates Shb 1, Shb } \\
8 \text {, Shb } 17 \text {, Shb } 27 \text { and Shb 2, Shb } 19 \text { and Shb } 26 \text { respectively. However, no correlation } \\
\text { was found between morphological groups and anastomosis grouping of isolates as all the } \\
\text { isolates belonged to only one anastomosis group (AG1-1A) on basis of observations on } \\
\text { hyphal anastomosis and their pathogenic reaction to rice, maize, soybean and wheat plants. }\end{array}$} \\
\hline Article Info & \\
\hline $\begin{array}{l}\text { Accepted: } \\
\text { 28 September } 2017 \\
\text { Available Online: } \\
\text { 10 November } 2017\end{array}$ & \\
\hline
\end{tabular}

\section{Introduction}

Rice (Oryza sativa L.) is the most important cereal crop of India. It is staple food crop of Jammu and Kashmir where it occupies 261.35 thousand hectare area with an annual production of 5001thousand tonnes in 2011 (Kaloo et al., 2014). Sheath blight of rice caused by Rizoctonia solani [Perfect stage: Thanatephorus cucumeris (Frank) Donk] is considered to be one of the most important diseases of rice occurring throughout the temperate and tropical rice production areas, being most prominent where rice is grown under intense, high fertility production system (Eizenga et al., 2002) and is now considered as most destructive disease of rice, next only to rice blast (Swain et al., 2005). Sheath blight of rice was first reported in India by Paracer and Chahal (1963), while from Kashmir it was reported by Mir (1986).

The disease can result in yield losses ranging from 20-50 per cent (Rajan, 1987).

However, under conditions of heavy severity, yield loss of more than 70 per cent has been reported from Chennai, India (Baby, 1992), and even complete crop failure has also been reported in Vietnam (Ou, 1992). 
The frequent failure in management of different plant diseases encountered for last many years have been explained partly due to evolution of pathogen strains/races resistant to a given set of fungicide formulations or overcoming a resistant gene in the host. The prevalence of few or many such races or strains of a pathogen in a given geographical area can also explain failure or success in management strategies for any disease. In case of $R$. solani, this problem is more complex since it ( $R$. solani) is not a discrete taxonomic unit but rather a "collective species" (Anderson, 1982) comprised of many related but apparently genetically isolated groups (Carling et al., 1994). Many different criteria have been used to delineate sub-groups of $R$. solani. Earlier methods of sub-grouping included differences in colony morphology, host range, virulence and other characters but perhaps the most widely used method of sub diving $R$. solani into smaller more homogenous groups is based on hyphal anastomosis (Carling and Summer, 1992). The sheath blight pathogen (R.solani) has been divided into 14 anastomosis groups (AGs) (Ogoshi, 1987, Carlin et al., 1994) and many Intra specific groups (ISGs) based on cultural, morphological and other characters. The present investigations were carried out to study the variability of $R$. solani isolates based on some cultural and morphological characters and correlate these characters with the identification of anastomosis group(s) of the fungal pathogen prevalent in Kashmir and the results are presented herein.

\section{Materials and Methods}

\section{Isolation, identification and maintenance of pathogen}

The rice sheath bits $(3-4 \mathrm{~mm})$ containing diseased and healthy sheath portions, were cut with sterilized scissors, surface sterilized in 1 per cent sodium hypochlorite solution for 1 minute, rinsed 2-3 times in sterilized distilled water, blotted dry and placed aseptically on potato dextrose agar (PDA) medium. Four such bits were placed on PDA in each Petri dish and incubated for two days at $28 \pm 2{ }^{\circ} \mathrm{C}$. The hyphal tips emanating from the tissue bits were cut off and transferred to PDA in Petri plates for purification and further growth of the pathogen. For identification, morphological characteristics such as shape, size and colour of sclerotia, branching type, septation and colour of mycelium, presence/absence of moniloid cells, growth rate etc, were observed under compound microscope and compared with standard description given by Parmeter and Whitney (1970).

Single sclerotial cultures of all the isolates were cultured separately on PDA and master cultures of these isolates were maintained on PDA slants in test tubes at $10 \pm 2{ }^{\circ} \mathrm{C}$ (Bolkan and Riberiro, 1985).

\section{Cultural and morphological characters}

Cultural and morphological parameters of each isolate like colony colour, sclerotial colour, size and formation pattern was recorded after inoculation of $R$. solani on to the sterilized PDA in $90 \mathrm{~mm}$ Petri plates incubated at $28 \pm 2{ }^{0} \mathrm{C}$ in B.O.D incubator after 15 days (Panja et al., 2011). The mycelial growth rate, however, was recorded after every 24 hours interval till the last Petri plate was completely colonized (60 hours). Five replications were maintained for each isolate.

\section{Anastomosis Grouping of $\boldsymbol{R}$. solani Isolates}

All the isolates collected were purified and confirmed to the current species concept of $R$. solani (Parmeter and Whitney, 1970). The isolates were subjected to hyphal tip anastomosis pairing in all possible 
combinations (Bolkan and Riberiro, 1985). The hyphal-agar discs (5 mm dia) of the $R$. solani isolates, to be tested for anastomosis, were placed $3 \mathrm{~cm}$ apart on sterilized glass slide coated with thin film of two per cent water agar. These slides were placed inside sterilized Petri plates containing moist blotter paper and incubated for 24 to 48 hours at $28 \pm 2{ }^{\circ} \mathrm{C}$. When both the test isolates grew and came in contact with each other, the slides were stained with 0.1 per cent aniline blue in lactophenol and observed under microscope (Singh et al., 1999). The anastomosis of each pairing isolates was repeated at least twice. The anastomosis group was identified on the basis of pathogenicity of isolates on rice, maize and wheat as per Ogoshi (1987).

\section{Results and Discussion}

\section{Morphological variability}

The sheath blight pathogen was isolated from all 27 isolates and examined for their cultural and morphological characteristics on PDA in $90 \mathrm{~mm}$ Petri plates. The results indicated that most of the rice isolates fall in five morphologically distinct groups, designated as $\mathrm{A}$ to $\mathrm{E}$ (Table 1, Plate 1). The colony colour varied from grey, light brown to dark brown.

The dark brown colony colour was exhibited by the isolates of group only $\mathrm{E}$, greyish by isolates of group $\mathrm{B}$, while all other isolates were light brown in colour. The isolates also differed in their growth rate. All the isolates were rapid growing, covering the Petri plate (90 $\mathrm{mm}$ diameter) in 48 hours except the isolates of group D and E, which covered the Petri plates ( $90 \mathrm{~mm}$ diameter) in 60 hours.

The colour of the sclerotia was dark brown in isolates of group $\mathrm{A}, \mathrm{C}$, and $\mathrm{E}$, while the isolates of group B and D produced light brown sclerotia. Two patterns viz., peripheral and central + scattered in sclerotial formation, were observed in the isolates of different groups. Peripheral sclerotial pattern was found in isolates of group A and B with an average diameter of 2.2 and $2.0 \mathrm{~mm}$, respectively, while all other isolates possessed central + scattered sclerotia. The isolates of group $\mathrm{C}$ possessed large central sclerotia (5.6mm diameter) formed by the fusion of few small sclerotia and some scattered sclerotia (av.2.6 $\mathrm{mm}$ diameter), whereas the isolates of group D possessed large central sclerotia (7.6 mm diameter) bearing some tan coloured ooze besides some scattered sclerotia (av.2.6 mm diameter).

\section{Hyphal anastomosis and pathogenicity}

The isolates belonging to different morphological groups were subjected to hyphal anastomosis in all possible combinations. All the isolates exhibited hyphal tip contact, cytoplasmic fusion and cell death (Table 2, Plate 2), indicating the presence of a single anastomosis group.

Inoculation of rice and maize plants with different morphological groups under poly house conditions produced typical sheath blight symptoms on rice and banded sclerotial disease on maize, suggesting the presence of anastomosis group AG-1-1A. The presence of anastomosis group AG-1-1B was ruled out because only typical sheath blight symptoms were observed on inoculated of rice plant while the absence of 'damping off' disease on inoculated wheat plants negated the possibility of the presence of anastomosis group AG-1-1C in isolates (Ogoshi, 1987).

Cultural and morphological variations were found among the sheath blight isolates collected from various locations during the survey. The isolates differ in colour of the colony, growth rate and size, shape, colour and pattern of sclerotia formation. 
Table.1 Morphological characteristics and growth habits of isolates of rice sheath blight pathogen, Rhizoctonia solani Kuhn

\begin{tabular}{|c|c|c|c|c|c|c|c|}
\hline \multirow[b]{2}{*}{$\begin{array}{c}\text { Isolate No. } \\
\text { (shb) }\end{array}$} & \multirow[b]{2}{*}{ Location } & \multicolumn{2}{|c|}{ Mycelial colony $^{*}$} & \multicolumn{3}{|c|}{ Sclerotial characteristics ${ }^{*}$} & \multirow{2}{*}{$\begin{array}{l}\text { Group } \\
\text { assigned }\end{array}$} \\
\hline & & Colour & Growth rate & Colour & $\begin{array}{l}\text { Size (av. } \\
\text { dia. } \mathbf{~ m m )}\end{array}$ & Formation pattern & \\
\hline 1 & Behama & Light brown & Moderate & Light brown & 2.6 & Central+scattered & $\mathrm{D}$ \\
\hline 2 & Nunner & Dark brown & Moderate & Dark brown & 2.4 & Central+scattered & $\mathrm{E}$ \\
\hline 3 & Tulmulla & Grey & Rapid & Light brown & 2.0 & Peripheral & $\mathrm{B}$ \\
\hline 4 & Tailbal & Light brown & Rapid & Dark brown & 2.2 & Peripheral & A \\
\hline 5 & Shalimar & Grey & Rapid & Light brown & 2.0 & Peripheral & $\mathrm{B}$ \\
\hline 6 & Batpura & Light brown & Rapid & Dark brown & 2.2 & Peripheral & A \\
\hline 7 & Kangan & Light brown & Rapid & Dark brown & 2.6 & Central + scattered & $\mathrm{C}$ \\
\hline 8 & Prang & Light brown & Moderate & Light brown & 2.6 & Central+scattered & $\mathrm{D}$ \\
\hline 9 & Wasun & Grey & Rapid & Light brown & 2.0 & Peripheral & $\mathrm{B}$ \\
\hline 10 & Pulwama & Light brown & Rapid & Dark brown & 2.2 & Peripheral & A \\
\hline 11 & Tahab & Light brown & Rapid & Dark brown & 2.6 & Central + scattered & $\mathrm{C}$ \\
\hline 12 & Rajpur & Grey & Rapid & Light brown & 2.0 & Peripheral & $\mathrm{B}$ \\
\hline 13 & Lissipora & Grey & Rapid & Light brown & 2.0 & Peripheral & $\mathrm{B}$ \\
\hline 14 & Nawpora & Light brown & Rapid & Dark brown & 2.2 & Peripheral & A \\
\hline 15 & Littar & Grey & Rapid & Light brown & 2.0 & Peripheral & $\mathrm{B}$ \\
\hline 16 & Kakpora & Grey & Rapid & Light brown & 2.0 & Peripheral & B \\
\hline 17 & Somber & Light brown & Moderate & Light brown & 2.6 & Central+scattered & $\mathrm{D}$ \\
\hline 18 & Gango & Light brown & Rapid & Dark brown & 2.2 & Peripheral & $\mathrm{A}$ \\
\hline 19 & Khudwani & Dark brown & Moderate & Dark brown & 2.4 & Central+scattered & $\mathrm{E}$ \\
\hline 20 & Sarandoo & Grey & Rapid & Light brown & 2.0 & Peripheral & $\mathrm{B}$ \\
\hline 21 & Kulgam & Light brown & Rapid & Dark brown & 2.6 & Central + scattered & $\mathrm{C}$ \\
\hline 22 & Achabal & Grey & Rapid & Light brown & 2.0 & Peripheral & $\mathrm{B}$ \\
\hline 23 & Khundroo & Grey & Rapid & Light brown & 2.0 & Peripheral & B \\
\hline 24 & Imoh & Light brown & Rapid & Dark brown & 2.2 & Peripheral & A \\
\hline 25 & & Light brown & Rapid & Dark brown & 2.6 & Central + scattered & $\mathrm{C}$ \\
\hline 26 & Veerinag & Dark brown & Moderate & Dark brown & 2.4 & Central+scattered & $\mathrm{E}$ \\
\hline 27 & Dooru & Light brown & Moderate & Light brown & 2.6 & Central+scattered & $\mathrm{D}$ \\
\hline
\end{tabular}

Observations recorded 15 days after incubation, Figures are average of 5 observations. Moderate $=$ covering Petri plate $(90 \mathrm{~mm}$ dia) in 60hrs; Rapid =covering Petri plate $(90 \mathrm{~mm}$ dia) in $48 \mathrm{hrs}$

Table.2 Identification of anastomosis group(s) of the isolates of Rhizoctonia solani Kuhn causing sheath blight of rice

\begin{tabular}{lcccccc}
\hline & Character observed & \multicolumn{2}{l}{ Reaction of the groups } & & & \\
\cline { 2 - 6 } & & A & B & C & D & E \\
\hline a) & Hyphal tip contact & + & + & + & + & + \\
b) & Cytoplasmic fusion & + & + & + & + & + \\
c) & Cell death & + & + & + & + & + \\
\multicolumn{2}{l}{ Reaction on } & & & & & \\
a) & Rice & Sh.B & Sh.B & Sh.B & Sh.B & Sh.B \\
b) & Maize & B.Sh.B & B.Sh.B & B.Sh.B & B.Sh.B & B.Sh.B \\
c) & Soybean & + & + & + & + & + \\
d) & Wheat & - & - & - & - & - \\
Anastomosis group (Ogoshi, 1987) & AG-1-1A & AG-1-1A & AG-1-1A & AG-1-1A & AG-1-1A \\
\hline
\end{tabular}

$\begin{array}{lll}+ & = & \text { Symptoms developed } \\ - & = & \text { No symptom development } \\ \text { Sh.B } & = & \text { Sheath blight } \\ \text { B.Sh.B } & = & \text { Banded sheath blight }\end{array}$


Plate.1 Morphological grouping of isolates (A, B, C, D and E) of Rhizoctoni solani Kühn on the basis of variation in culture on PDA
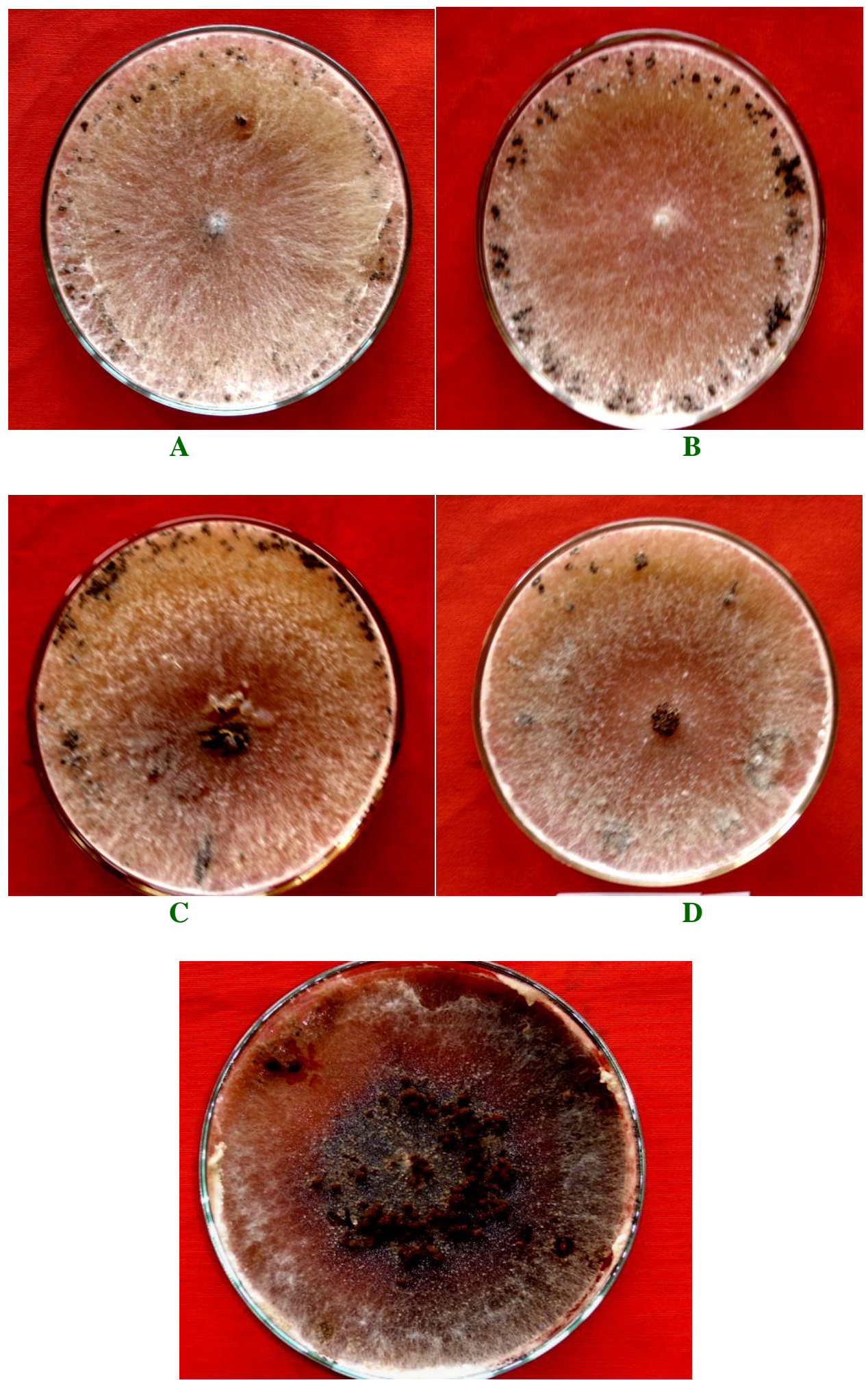

$\mathbf{E}$ 
Plate.2 Morphology and anastomosis reaction of Rhizoctonia solani Kühn

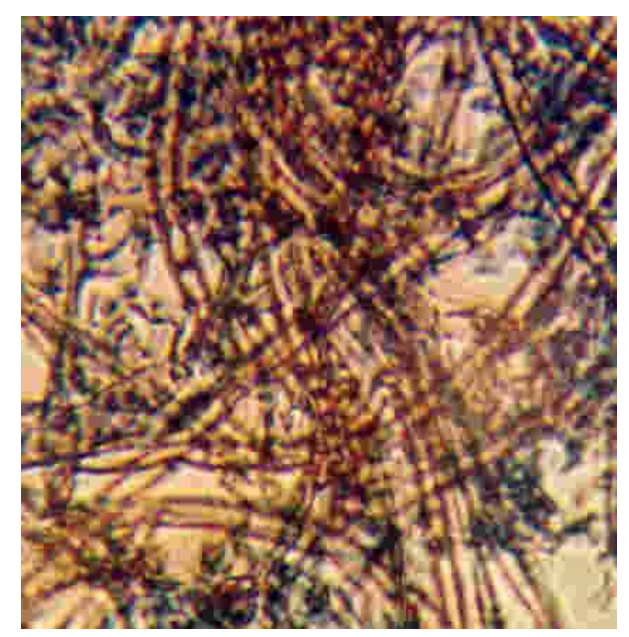

Mycelium

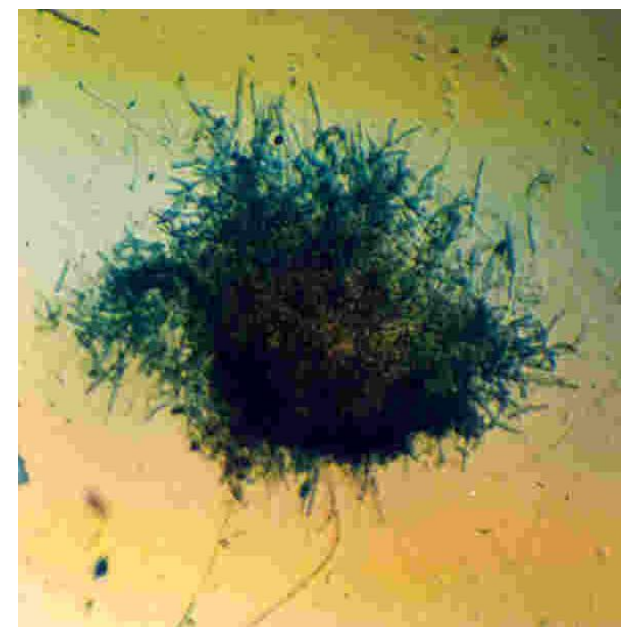

Sclerotium

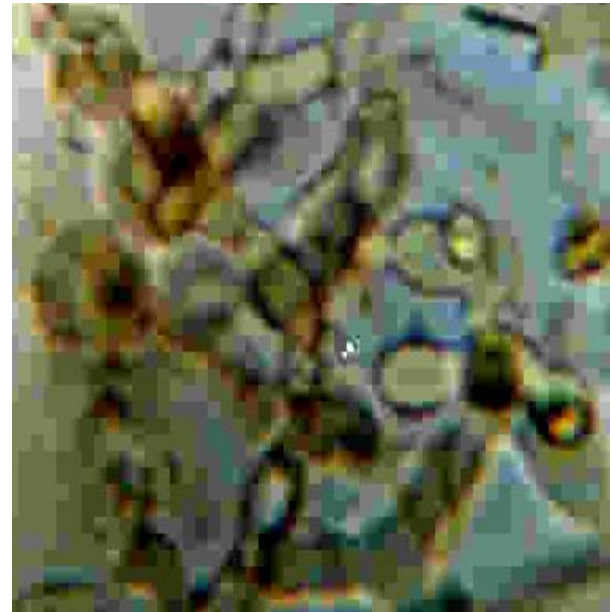

Moniloid cells

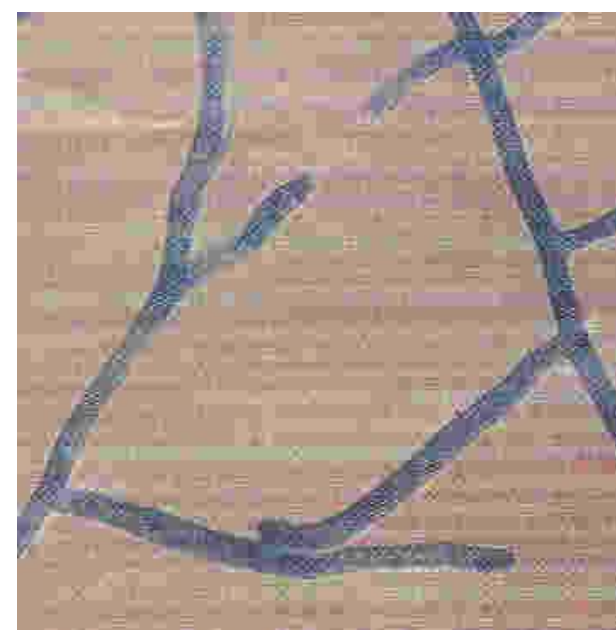

Hyphal contact

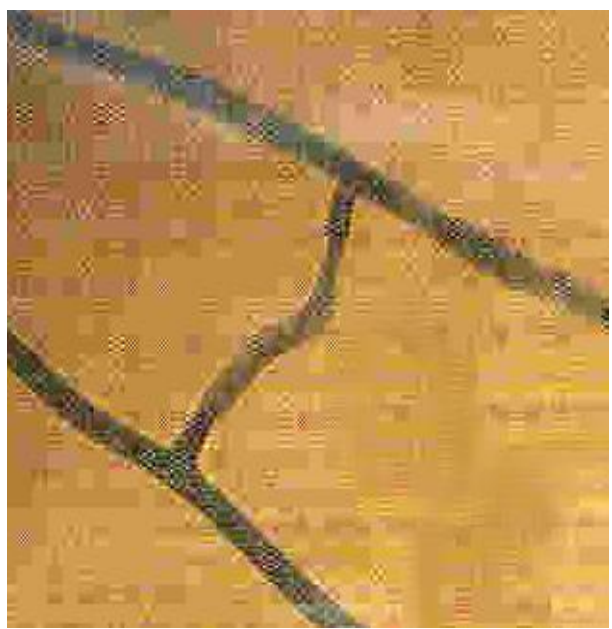

Hyphal tip fusion 
The colour varied from light brown, greyish brown to dark brown while sclerotial average diameter ranged from 2.0-2.6 $\mathrm{mm}$. The isolates when were subjected to anastomosis, all showed positive hyphal fusion, in all possible combinations and thus suggesting the presence of single anastomosis groups.

Cultural and morphological variation in $R$. solani have been reported by various workers viz., Singh et al., (1999), Panja et al., (2011) etc. The finding that cultural and morphological variations have no relationship with the anastomosis or pathological behaviours is in accordance with the findings of Singh et al., (1999). Anastomosis group, AG-1-1A was identified on the basis reaction of the representative sheath blight isolates to maize, soybean, wheat and rice in accordance with Ogoshi (1987). Various research workers across the country have also identified AG-11A of $R$. solani as causal organism of rice sheath blight in India. Singh et al., (1990) also reported AG-1 group from the isolates of $R$. solani, which showed different morphological characteristics in culture, collected from five different sheath blight endemic locations, viz., Assam, Andhra Pradesh, Tamil Nadu and Andaman, India. Singh et al., (1999) while investigating the relationship among cultural/morphological characteristics, anastomosis behaviour and pathogenicity of $R$. solani on rice found that all the rice isolates of $R$. solani belonged to AG-1-1A.

\section{References}

Anderson, N.A., 1982. The genetics and pathology of Rhizoctonia solani. Review of Phytopathology 20: 329-347.

Baby, U.I., 1992. Studies on the control of rice sheath blight through the integration of fungal antagonists and organic amendments. Tropical Agriculture 70: 240-244.

Bolkan, H.A. and Ribeiro, W.R.C., 1985.
Anastomosis groups and pathogenicity of Rhizoctonia solani isolates from Brazil. Plant Disease 69: 599-601.

Carling, D.E. and Summer., D.R. 1992. Rhizoctonia. In: Methods of Research on Soil borne Phytopathogenic Fungi (Eds. L.L. Singleton, J.D. Mihail and C.M. Rush). American Phyto pathological Society, pp 157-165.

Carling, D.E., Rothrock, C.S., Macnish, G.S., Sweetingham, M.W., Brainard, K.A. and Winters, S.W., 1994. Characterization of anastomosis group 11 of Rhizoctonia solani. Phytopathology 84: 1387-1392.

Eizenga, G.C., Lee, F.N. and Rutger., J.N. 2002. Screening Oryza species plants for rice sheath blight resistance. Plant Disease 66: 808-812.

Mir, N.M., 1986. Important Diseases of Rice. Rice Production Training Programme Manual Rice Research Station, SKUAST, Khudwani, Anantnag (J\&K), pp 54-56, June $23^{\text {rd }}-26^{\text {th }}$

Ogoshi, A., 1987. Ecology and pathogenicity of anastomosis and intraspecific groups of Rhizoctonia solani Kuhn. Annual Review of Phytopathology 25: 125-143.

Ou, S.H., 1992. Rice Diseases. Commonwealth Mycological Institute, Kew, England, p. 368.

Panja, B.N, Das, A, Mazumdar, P and Shah, J. 2011. Virulence prediction of Rhizoctonia solani Kuhn based on pathogenic and cultural variability. Journal of Mycopathological Research 49(2): 247-255.

Paracer, C.S. and Chahal, D.S., 1963. Sheath blight of rice caused by Rhizoctonia solani Kühn, a new record in India. Current Science 32:320-329.

Parmeter, J.R. and Whitney, H.S., 1969. Taxonomy and nomenclature of the imperfect state- Rhizoctonia solani. In: (Ed. J.R. Parmeter). Biology and Pathology. University of California 
Press, Berkley.

Parmeter, J.R. and Whitney, H.S., 1970.

Taxonomy and nomenclature of the imperfect state- Rhizoctonia solani. In: (Ed. J.R. Parmeter). Biology and Pathology. University of California Press, Berkley University of California Press, Berkelay, Los Angeles and London.

Rajan, C.P.D., 1987. Estimation of yield losses due to sheath blight disease of rice. Indian Phytopathology 40: 174177.

Singh, A., Singh, U.S., Willorquet, L., Savary, S. and Singh, A., 1999. Relationship among cultural/ morphological characteristics, anastomosis behaviour and pathogenecitiy of Rhizoctonia solani Kühn on rice. Journal of Mycology and Plant Pathology 29(3): 306-316.

Singh, S.K., Satyanarayana, K. and Reddy, A.P.K., 1990. Studies on morphology, growth habit, hyphal anastomosis and virculence pattern of fine isolates of sheath blight pathogen of rice. Indian Phytopathology 43(3): 368-371.

Swain, N.C., Chhotray, A.K. and Mahapatra, S.S., 2005. Pathogenic variability of Rhizoctonia solani causing sheath blight od paddy and it managementent. Journal and Plant Protection and Environment. 2 (1): 96-99.

\section{How to cite this article:}

Mohammad Najeeb Mughal, Sabiya Bashir, Nazir A. Bhat and Bhat, K.A. 2017. Cultural and Morphological Variability and Identification of Anastomosis Group of Rhizoctonia solani (Thanatephorus cucumeris) Causing Sheath Blight of Rice in Kashmir. Int.J.Curr.Microbiol.App.Sci. 6(11): 3787-3794. doi: https://doi.org/10.20546/ijcmas.2017.611.443 